\title{
Research on Statistical Accounting Methods for Ecological Civilization in China
}

\author{
Shi Qingyan Zhou Jing
}

Research Institute of Statistical Sciences, National Bureau of Statistics of China, Beijing 100826, China

\begin{abstract}
The fundamental work in ecological civilization construction begins with the creation of an accounting and statistical system that can provide reliable data support for the purpose of monitoring, evaluation, and decision-making. Although there are data on the resources and environment of China, they cannot be effectively integrated into a unified framework due to the lack of a top-level accounting and statistical framework of ecological civilization. Considering the actual demands of ecological civilization construction, this study analyzes the problems that exist in the accounting and statistical system of ecological civilization in China and constructs a statistical indicator system and an accounting framework of ecological civilization. Further, it gives suggestions for the improvement of the accounting and statistical system of ecological civilization in China.
\end{abstract}

Keywords: ecological civilization; SEEA2012-CF; statistical system; accounting framework; natural resources balance sheet; environmental assets account

\section{Introduction}

The ecological progress is an important part of the overall plan for promoting all-round economic, political, cultural, social, and ecological progress in building socialism with Chinese characteristics and a major strategy concerning China's economic and social development quality, people's wellbeing and China's future. Building a solid ecological progress statistical system is the fundamental work for ecological progress, which aims to provide ecological progress with information base, monitoring, early warning, and decision making supports.

In order to meet the national strategic requirements on promoting ecological progress, China's ecological progress statistical accounting should be supplemented and expanded on the basis of existing resources and environment statistical accounting: from laying the emphasis on pollution control and the improvement of resource utilization efficiency to attaching equal importance to the improvement of ecological environ- ment and pollution control and the improvement of resource utilization efficiency, from focusing on the flow statistics of resource and environment to attaching equal importance to the flow and stock statistics of resource and environment. The System of Environmental-Economic Accounting 2012-Central Framework (SEEA2012-CF) [1] released by the United Nations and other international organizations is the international standard for environmental economic accounting, and the System of Environmental-Economic Accounting 2012-Experimental Ecosystem Accounting [2] covers special topics that cannot be agreed upon but are closely related to the policy, which serves as a useful reference for the building of the statistical accounting system framework of ecological progress in China. Based on the analysis of the present situation of the statistical accounting of ecological progress in our country, this paper puts forward the basic framework of ecological progress statistical accounting and suggestions to further improve China's ecological progress statistical accounting system.

Received date: June 16, 2017; Revised date: July 3, 2017

Corresponding author: Shi Qingyan, Statistical Science Institute of National Bureau of Statistics of the PRC, Research Fellow. Major research field is economic statistics. E-mail: shiqy@stats.gov.cn

Funding program: CAE Advisory Project “Several Strategic Issues on Eco-Civilization Construction (Phase II)” (2015-ZD-16)

Chinese version: Strategic Study of CAE 2017, 19 (4): 067-073

Cited item: Shi Qingyan et al. Research on Statistical Accounting Methods for Ecological Civilization in China. Strategic Study of CAE, https://doi.org/10.15302/ J-SSCAE-2017.04.011 


\section{The current situation and existing problems of the statistical accounting of ecological progress in china}

\subsection{The current situation of the statistical accounting of ecological progress in China}

The statistics of ecological progress is not a new statistical work and statistical field. In recent decades, the rigid constraints of resources and environment on social and economic development have become gradually apparent, and the sustainability of development has become a global issue. As a mirror of social and economic development, statistics can objectively reflect the problem. Canada, Australia and other countries with rich natural resources take a leading position in environmental and economic accounting and accumulated rich practical experience [3].

China's relevant governmental departments have established the corresponding resource and environment statistical system in their management practice for years, and the status of resources and environment statistics in the government statistics is increasing over time. So far, the resource and environmental statistics system in China mainly includes: statistics of land resources, mineral and energy resources by departments of land and resources, the statistics on survey of the quality of farmland by agricultural departments, water resources statistics by water conservancy departments, forest and forestry statistics by forestry departments, the statistics on monitoring of resource quality and ecological function by environmental protection departments [4]. The statistics of these departments provide an important basis for the statistical accounting of ecological progress in China.

As for environmental resource accounting, the System of National Accounts of China (2002) [5] has included the natural resource accounting table, covering the four kinds of resources - forest, water, land, and mineral resources. Although it did not provide comprehensive accounting data, it showed that the system of national accounts of China had taken into account some problems of resources and environmental accounting, which provides a basic starting point and foundation for China's environmental economic accounting [6]. In 2004, the National Bureau of Statistics and the State Forestry Bureau jointly launched the program of Research on Green GDP and Accounting of Forest Resources in China for the first time, which put forward the theory of and methods for accounting of forest resources, built China's forest-based green national economic accounting framework and measured and calculated relevant data on the basis. In 2013, the two departments jointly carried out the second-round Research on China's Forest Resources Accounting and Green Economy Evaluation System, and produced China's Forest Resources Accounting in the Context of Ecological Institutional Development [7]. In addition, the National Bureau of Statistics worked with the State Environmental Protection Administration and the Ministry of Water Resources respectively to conduct re- searches on the green national economic accounting and the water resources accounting $[8,9]$. The recent significant progress in environmental economic accounting is that the National Bureau of Statistics carried out the pilot work of developing the natural resource balance sheet in 2015, and the accounting contents include land resources, forest resources, and water resources. The preparation of the natural resource balance sheet will be conducted nationwide.

\subsection{Problems with the existing system of statistical accounting of ecological progress in China}

Although China's ecological progress statistical accounting system has certain institutional foundation and data conditions, there are still problems as follows.

(1) The lack of a complete set of environmental economic accounting institution. Although the international standard SEEA2012-CF has been issued, China has not yet formulated a relatively complete and unified environmental economic accounting institution. Due to the lack of top-level design of environmental economic accounting institution, not only the comprehensive and systematic accounting work cannot be carried out, but also the researches on resources and environmental accounting in some areas conducted by relevant departments are of great randomness.

(2) The statistical institutions and methods of different departments need be coordinated. The basic data for ecological progress statistics are scattered in departments of land and resources, water conservancy, forestry, agriculture, and environmental protection, etc. However, the data between departments are fragmented, the standards are different, and there is severe data blockade. The difference between the departmental statistics institutions and framework as well as the data segmentation lead to inconsistency of indicators and data in aspects of definition, scope, caliber, source and method, thus resulting in that the data is nonstandard and difficult to be integrated in the process of statistical accounting.

(3) The scope and methods of statistical accounting need to be expanded and studied. China's current statistical accounting of ecological progress is limited to specific fields and physical-quantity accounts, with a big gap from the accounting scope required by SEEA2012-CF, and value-quantity accounts have not yet started. Therefore, we need to expand the scope of statistical accounting of ecological progress and speed up the research on the valuation theories and methods of value-quantity accounts so as to improve the statistical accounting of ecological progress in the future.

\section{The design for the basic framework of China's ecological progress statistical accounting system}

This section starts from the actual demand for making eco- 
logical progress in China and discusses the basic framework of the ecological progress statistical accounting system with reference to SEEA2012. The statistical indicator system and the accounting framework are the most important parts of the ecological progress statistical system. This section discusses these two aspects respectively.

\subsection{The statistical indicator system of ecological progress in China}

A complete "ecological progress statistical indicator system" should not only reflect the quantity and quality of environmental media, natural phenomena and the impact of socio-economic activities on the ecological environment, but also reflect relevant activities of ecological progress [10]. The ecological progress statistical indicator system constructed in this study covers three aspects of environmental assets, environmental quality and environmental activities (Table 1).

\subsubsection{Environmental assets}

Environmental assets are natural life and non-living elements on Earth, which together constitute the biological environment that benefits human beings. Environmental assets include the six categories - mineral and energy resources, land resources, soil resources, forest resources, aquatic resources, and water resources. In the statistical system of environmental assets, the statistical indicators of each environmental asset can be divided into the flow indicator and the stock indicator. The flow indicator is used to measure the flow of environmental assets during the accounting period, such as the input, depletion, increase or type change of assets, while the stock indicator reflects the initial and closing stock of all kinds of environmental assets. According to the difference in data acquisition of indicators, the data can be divided into physical data and value data. Generally, physical data is easier to obtain, while the value data of environmental assets can be obtained on the basis of physical data if the environmental assets can be evaluated.

\subsubsection{Environmental quality}

Environmental quality reflects environmental pollution and environmental events. Environmental pollution mainly reflects the discharge of harmful substances from agriculture, industry and urban life to the environment, including wastewater discharge, exhaust emission and solid waste discharge. Environmental events refer that pollutants or radioactive substances and other toxic and harmful substances enter environmental media such as the atmosphere, water, soil, causing damage to the ecological environment due to pollutant emissions, natural disasters or production safety accidents, which require urgent measures. It includes geological, earthquake, marine, forest disaster, environmental pollution, and damage accidents.

\subsubsection{Environmental activities}

Environmental activities include economic activities that are mainly aimed at reducing or eliminating environmental pressure or making effective use of natural resources. Environmental

Table 1. Design of China's ecological progress statistical indicator system.

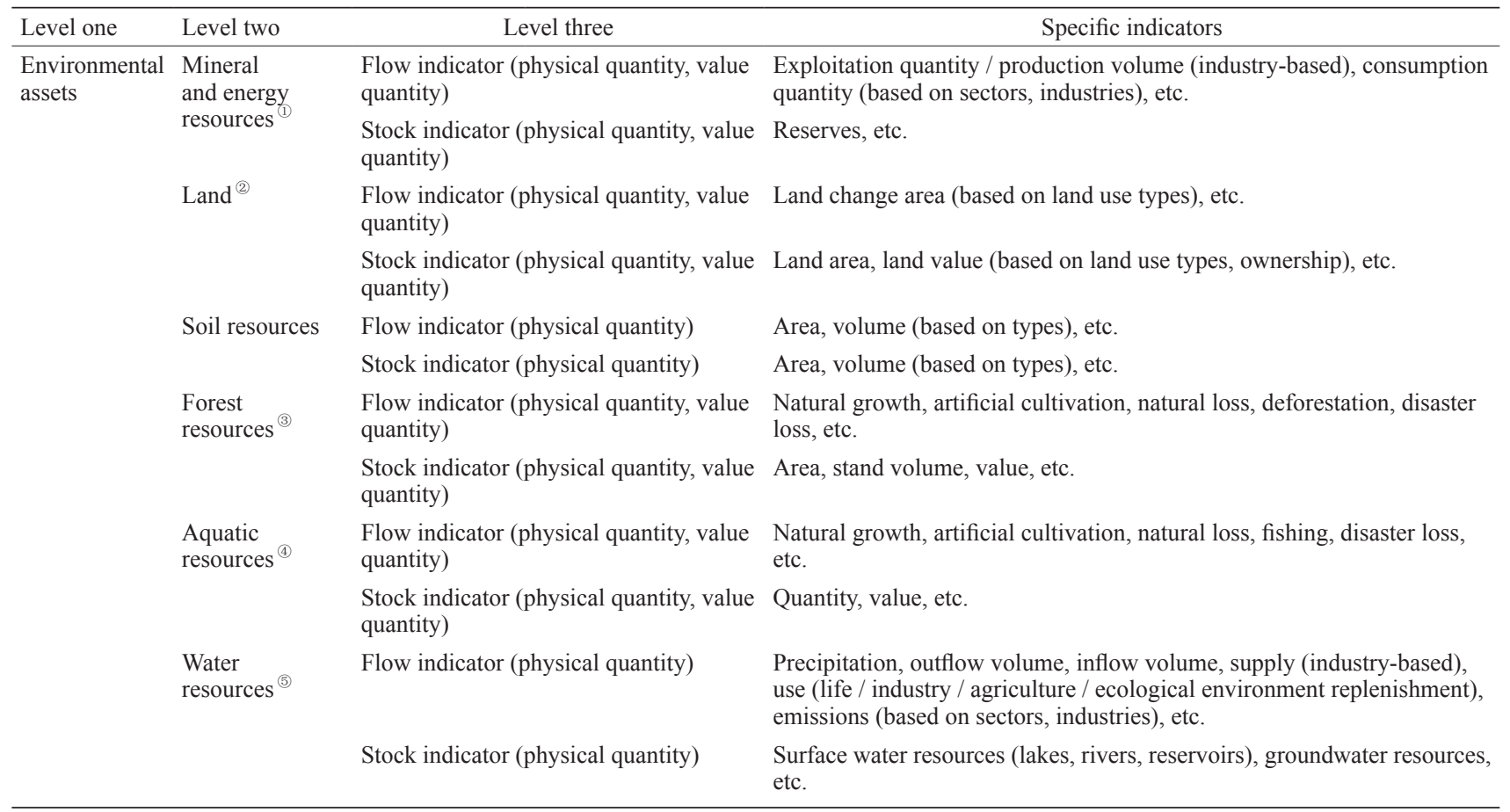


Table 1. (Continued table)

\begin{tabular}{|c|c|c|c|c|}
\hline Level one & Level two & & Level three & Specific indicators \\
\hline $\begin{array}{l}\text { Environmental } \\
\text { quality }\end{array}$ & $\begin{array}{l}\text { Environmental } \\
\text { pollution }\end{array}$ & $\begin{array}{l}\text { Wastewater } \\
\text { discharge }\end{array}$ & $\begin{array}{l}\text { Wastewater discharge } \\
\text { amount }\end{array}$ & $\begin{array}{l}\text { Industrial wastewater, urban domestic sewage, sewage discharge of } \\
\text { centralized treatment facilities, etc. }\end{array}$ \\
\hline & & & $\begin{array}{l}\text { Chemical oxygen } \\
\text { demand and emission }\end{array}$ & $\begin{array}{l}\text { Industrial wastewater, agricultural chemistry, urban domestic sewage, } \\
\text { chemical oxygen demand and emission of centralized treatment facilities, } \\
\text { etc. }\end{array}$ \\
\hline
\end{tabular}
etc.

Ammonia-nitrogenous Industrial waste water, agriculture, urban domestic sewage, ammoniaemissions nitrogenous discharge of centralized treatment facilities, etc.

Exhaust Sulfur dioxide emission emissions

Nitrogen oxide emissions

Smoke (powder) dust emissions Sulfur dioxide emissions of industries, urban life, centralized treatment facilities, etc.

Nitrogen oxide emissions of industries, urban life, vehicles, centralized treatment facilities, etc.

Smoke (powder) dust emissions of industries, urban life, vehicles, centralized treatment facilities, etc.

Solid waste General industrial discharge solid waste

Production of general industrial solid waste, dumping and discarding of general industrial solid waste, etc.

Hazardous waste

Environmental Geological disasters

events Earthquake

Forestry Forest fire

disaster

Forest pests and diseases

Ocean disaster

Emergent environmental events

Environmental Environmental Environmental Water quality activities protection

monitoring

Air quality monitoring

Soil monitoring

Noise monitoring

Environmental Wastewater treatment governance

Exhaust gas treatment Solid waste treatmen

Governance cost and investment

Resource Afforestation management
Water logging control and conservation of water and soil

Natural conservation
Production of hazardous waste, dumping and discarding of hazardous waste, etc.

Number of occurrences, casualties, affected area, direct economic loss, etc.

Number of occurrences, earthquake magnitude, casualties, direct economic loss, etc.

Number of occurrences, disaster level, total fire area, affected forest area, loss of forest stand volume, casualties, etc.

Area of occurrence, area of prevention and control, prevention and control rate, etc.

Number of occurrences, number of deaths and missing persons, direct economic loss, etc.

Number of occurrences, casualties, direct economic loss, etc.

Water quality monitoring of surface water (river, lake and reservoir), water quality evaluation of sea water (coastal waters, the whole sea), etc.

PM10 concentration, PM2.5 concentration, sulfur dioxide concentration, nitrogen dioxide concentration, days of air quality reaching and surpassing Grade-II, etc.

Soil quality grades, etc.

Road traffic noise monitoring, regional environmental noise monitoring, etc.

The amount of industrial wastewater treatment, the amount (rate) of urban sewage treatment, etc.

The amount of industrial waste gas treatment, etc.

Comprehensive utilization amount (rate) of general industrial solid waste, general industrial solid waste disposal amount (rate), comprehensive utilization amount (rate) of hazardous waste, hazardous waste disposal amount (rate), innocent treatment amount (rate) of household garbage, etc.

Operation cost of industrial wastewater treatment facilities, operation cost of industrial waste gas treatment facilities, operation cost of hazardous waste concentrated disposal plants, operation cost of urban sewage treatment plants, mine environmental recovery and governance funds, investment completed this year for pollution prevention and control of industrial enterprises, etc.

Forest coverage rate, wetland area, afforestation area, completion amount of forestry investment, green coverage rate of urban built-up area, per capita park green area, etc.

Water logging control area, area of water and soil erosion control, completed investment of soil and water conservation and ecological projects, etc.

Number of protected areas (national-level, provincial-level), area of protected areas (national-level, provincial-level), number of geological parks, investment in construction of nature reserves, investment in construction of geological parks, etc.

Number of ecological cities and counties, etc.

Construction of eco-regions

\footnotetext{
${ }^{(1)}$ Mineral and energy resources include petroleum, natural gas, coal, metal minerals and non-metallic minerals; ${ }^{(2)}$ the land includes agricultural land and construction land; ${ }^{(3)}$ forest resources include natural forest resources and cultivated forest resources; ${ }^{4}$ aquatic resources include wild aquatic resources and cultivated aquatic resources; ${ }^{5}$ water resources include surface water and underground water.
} 
activities include environmental protection and resource management. Environmental protection refers to various activities aiming for preventing, reducing and eliminating pollution and other environmental degradation problems, which can be further divided into environmental monitoring and environmental governance. Environmental monitoring refers to the natural environment quality monitoring, including the monitoring of air, water, soil, noise, etc. Environmental governance refers to activities to reduce the emissions of hazardous substances to the nature, including the disposal of waste water, exhaust gas and solid waste as well as the governance and investment. Resource management activities refer to activities that aim to protect and maintain existing natural resources to prevent them from decreasing. These activities include the recovery of existing natural resources, such as afforestation, water logging control and conservation of water and soil, and maintain the specific functions or quality of natural environment through the establishment of nature reserves and construction of eco-regions, etc.

\subsection{China's ecological progress accounting system framework}

The objectives of the ecological progress accounting framework are: First, the process of ecological progress in China can be reflected via resources and environmental accounting. Second, through integrating the resources and environmental accounting with the national economic accounting into a unified framework, and analyzing the relationship and mutual impacts of natural resources, ecological environment and national economy, we explore the harmonious development mode of "pursuing economic advancement while protecting ecological environment". The building of the ecological progress accounting framework is a complex, systemic and long-term work, it is suggested that we should, based on the related work that has been carried out in China, follow the thinking of "going from simple to complex, from focused to comprehensive, from single to integrated" and implement the "three phases" strategy, and gradually improve the ecological progress accounting framework in China (Fig. 1).

Phase 1: Preparing the natural resource balance sheet. The preparation of natural resources balance sheet is the first step of comprehensive ecological progress accounting. The National Bureau of Statistics has carried out the pilot work for developing a natural resources balance sheet that makes statistics of stock and changes of land resources, forest resources and water resources, which is more similar to assets accounts in the environmental economic accounting for there is no reflection of liabilities. To better promote ecological progress, natural resources balance sheet should not only reflect the condition of assets, but also reflect the liabilities, that is, it should cover both the environmental assets and the environmental liabilities of the subjects of ecological responsibility. Therefore, the next step is to improve the natural resources balance sheet from the following two aspects: First, it is to increase the environmental liabilities accounting. The liability party should keep accounts of the environmental protection responsibility, resource management responsibility and possible natural phenomena responsibility that should be recognized in accordance with the accrual basis principle in the process of developing and utilizing natural resources. Second, it

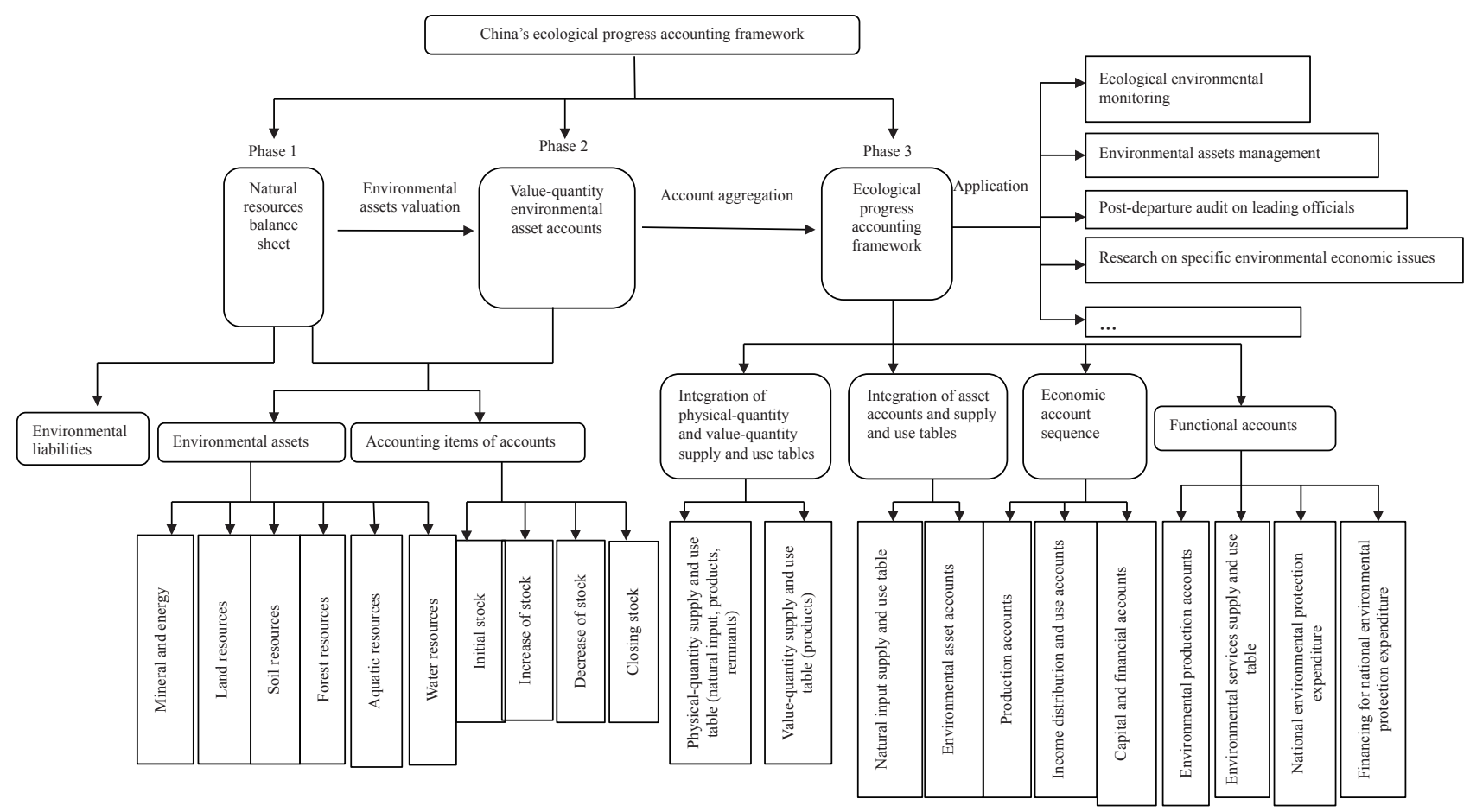

Fig. 1. Diagram of China's ecological progress accounting framework. 
is to expand the scope of environmental assets accounting. The existing three kinds of environmental assets accounting will be expanded to such six kinds of environmental assets as mineral and energy resources, land resources, soil resources, forest resources, aquatic resources and water resources.

Phase 2: Preparing value-quantity environmental asset accounts. The environmental assets of the natural resources balance sheet are usually recorded in physical units. The advantage of physical-quantity environmental assets accounts is conducting classified management and monitoring of environmental assets, however, different physical units of environmental assets make it impossible to unify different types of environmental assets and to integrate them with the national economic accounting system which adopts the monetary unit. Therefore, it is quite necessary to develop value-quantity environmental asset accounts on the basis of physical-quantity environmental asset accounts. The structures of the two are basically the same, and the main difference is value-quantity environmental asset accounts adopt monetary units, thus the key and difficult part in compiling value-quantity environmental asset accounts is the valuation of environmental assets. Internationally, valuation methods including the market price method and the net present value of future earnings are recommended, and appropriate valuation methods should be selected according to different asset categories.

Phase 3: Accomplishing the correlation and integration between environmental asset accounts and national economic accounts to form a complete and unified accounting system of ecological progress. In order to reflect the intrinsic connection between natural resources and national economic development, the following four aspects can be integrated. First, the integration of supply and use tables of physical quantity and value quantity. The physical-quantity supply and use table (natural input, products, and remnants) and the value-quantity supply and use table (products) are consolidated; second, the integration of asset accounts and the supply and use tables; third, the economic account sequence is created to display all environment-related to transactions and flow information; fourth, the creation of functional accounts. Such accounts record economic activities about the environment in monetary units, including the two categories of environmental protection and resource management. In addition, the combination of various environmental and economic data with other data concerning employment, population, etc. can further expand the application scope of ecological progress accounting.

\section{Suggestions on improving the ecological progress statistical system of China}

\subsection{Establishing a sound environmental economic accounting institution in line with SEEA2012-CF}

The statistical accounting of ecological progress is a compli- cated systemic engineering. In order to integrate with the international statistical accounting system, China should, based on the current data, develop an environmental economic accounting institution as soon as possible that meets the needs of economic development and ecological management and is in line with the SEEA2012-CF. This institution shall include a set of laws, regulations, methods, measures and management modes, and its core is to build the basic framework of China's environmental economic accounting system. The environmental economic accounting system includes accounting principles, concept definition, account setting, data collection, indicator construction, method selection, quality control, which is an overall framework that guides the future compilation and improvement of environmental economic accounting accounts at the top-design level, and also guides the improvement of statistics about environmental resources. The basic principles for constructing this framework include: First, the construction should extensively refer to international experience, comply with SEEA2012-CF as far as possible, adapt to China's reality, be based on the practical experience of environmental economic accounting in China, reflect China's economic and environmental characteristics, and maintain convergence with China's existing statistical and accounting basis. Second, it should be inclusive, so as to constantly take in new content and methods to enrich China's environmental economic accounting.

\subsection{The valuation method should be one of the research} focuses

Physical accounting is the first step of environmental economic accounting, while value accounting is the comprehensive accounting based on physical accounting and represents the ultimate goal of environmental economic accounting. For China, a large country with rich and widely distributed resources, it is obvious that the valuation of natural resources is difficult and crucial. The research on resources and environment evaluation in our country is lagging behind, therefore, we should hurry up to carry out researches on valuation of different types of natural resources, so as to provide technical support for setting up the value account of environmental economic accounting.

\subsection{Improving the organizations of ecological progress statistical accounting}

In view of the non-convergence of statistical institutions of different governmental departments and fragmented data, it is suggested that, led by the National Bureau of Statistics, in coordination with ecological environment and natural resources management departments including National Development and Reform Commission, Ministry of Finance, Ministry of Land and Resources, Ministry of Environmental Protection, Ministry of Water Resources, Ministry of Agriculture, State Forestry Ad- 
ministration, and State Oceanic Administration, the ecological progress statistical accounting coordination group should be set up. Its purpose is to conduct top-level design for the ecological progress statistical system framework on the basis of existing statistical accounting basis of all departments and the study on actual needs of ecological progress. Specific responsibilities include: meet the management objectives of competent departments, build a unified ecological progress statistical accounting framework to integrate the ecological progress statistics of each department. Some statistics businesses which are overlapping or adopt different institutions and methods should be coordinated by standardizing the statistical standards, caliber and methods, so as to resolve the data conflict and inconsistency between departments. The sharing and convergence of statistical data should be achieved through timely establishment of communication mechanisms and channels among various departments. For important statistical indicators which are lacking at the moment, the corresponding statistical survey institution shall be studied to fill in the data gap by means of conventional statistics or supplementary survey.

\section{References}

[1] United Nations, European Commission, Food and Agriculture Organization of the United Nations, etc. System of environmental economic accounting 2012-central framework [M]. New York: United Nations, 2014.

[2] United Nations, European Commission, Food and Agriculture
Organization of the United Nations, etc. System of environmental economic accounting 2012-experimental ecosystem accounting [M]. New York: United Nations, 2014.

[3] Gao M X, Mu Y N. Resources and environmental statistics related to sustainable development-Evolution of the topics of resources and environment in China statistical yearbook [J]. China Statistics, 2011(5): 44-45. Chinese.

[4] Alexander R, Sokol Vako, Julian Chow, et al. The system of environmental-economic accounting [R]. Shanghai: National Bureau of Statistics of China, United Nations Statistics Division, 2015.

[5] National Bureau of Statistics. System of national accounts of China (2002) [M]. Beijing: China Statistical Publishing House, 2003. Chinese.

[6] Gao M X. The significance of SEEA-2012's release on the implementation of environmental-economic accounting [J]. Journal of Renmin University of China, 2015, 29(6): 47-55. Chinese.

[7] Research Team of the China Resource Accounting Program. China's forest resources accounting in the context of ecocivilization institutional development $[\mathrm{M}]$. Beijing: China Forestry Publishing House, 2015. Chinese.

[8] Ministry of Environmental Protection, National Bureau of Statistics. Study report 2004 for green national economic accounting [J]. Environmental Protection, 2006(18): 22-29. Chinese.

[9] Ruan R L, Ruan D C, Zhang Y, et al. Research on the statistics and accounting system for Shanghai water resources [M]. Beijing: China Science Publishing \& Media Ltd., 2012. Chinese.

[10] Mu Y N. Exploration of the measurements of resources and environments from the official statistics perspective [J]. Modern Management Science, 2012(11): 35-36. Chinese. 